\title{
La ciudad en el cine de superhéroes
}

\author{
Arturo Encinas CantalapiedRa \\ Departamento de Humanidades \\ Universidad Francisco de Vitoria \\ a.encinas.gen7@ufv.es
}

Recibido: $14 / 03 / 2013$

Modificado: $11 / 08 / 2013$

Aceptado: 01/10/2013

\section{Resumen}

En el presente trabajo analizamos la imagen de la ciudad en el cine de superhéroes a través de: el estudio de la ciudad como signo de los valores democráticos y la relación del superhéroe con las leyes, el papel narrativo de la ciudad y su realización cinematográfica, la ciudad como escenario de la lucha entre villanos y superhéroes, y los medios de comunicación como factor determinante en la relación entre el superhéroe y la ciudadanía. Cuando mencionamos la "ciudad", también nos referimos a los ciudadanos además de a las estructuras urbanas.

Palabras clave: cine, superhéroes, ciudad, medios de comunicación, democracia.

Title: The city in the superheroes movies

\section{Abstract}

In this paper we analyze the image of the city in the superhero film through: the study of the city as a sign of democratic values and the relationship of the superhero with the laws, the role of the narrative city and its filmmaking, the city as the setting for the fight between superheroes and villains, and the mass media as a determinant factor in the relationship between the superhero and citizenship. When we mention the word "city", we also refer to citizens as well as to urban structures.

Keywords: movies, superheroes, city, mass media, democracy.

\section{Índice}

1. Introducción

2. La ciudad como signo de los valores democráticos

3. Los planos que retratan la ciudad en el cine de superhéroes

4. La ciudad como escenario de la lucha

5. Los medios de comunicación: conciencia colectiva de la ciudad 


\section{Introducción}

Existe una relación de retroalimentación entre el cine que vemos y lo que somos. En cada película se presenta una cosmovisión que no es mera explicación o interpretación de una realidad, pues también influye en el espectador (Orellana y Martínez Lucena 2010: 19). Por su parte, la ciudad, entorno posmoderno de referencia, siempre ha gozado de un lugar privilegiado en el contexto argumental fílmico. El retrato urbano que nos ocupa en el presente trabajo es el que ofrece un tipo de cine que desde hace unos años está viviendo un exitoso resurgir: el cine de superhéroes, cuyos protagonistas ya se han convertido en parte de nuestro lenguaje cultural (Morris 2010: 15). Estos filmes nos confirman que no hay cine de superhéroes sin referencias urbanas, pues los valores por los que lucha el superhéroe están significados en la ciudad; estos son, en líneas generales, la justicia y la democracia.

El superhéroe tiene la firme convicción de que es necesario proteger a la ciudad -su ecosistema artificial. Llegamos a encontrar casos en los cuales la opción en favor de la integridad física de la ciudad es lo que, en cuestión de minutos, convierte a una persona con capacidades extraordinarias en un superhéroe. Por el contrario, el exterminio de la ciudad convierte al superpoderoso, y también a quien no lo es, en villano. Así ocurre en Chronicle (Trank, dir., 2012). Tanto Andrew Detmer como Matt Garetty han adquirido superpoderes y los utilizan. En el tramo final de la película, sus actitudes hacia el contexto urbano establecen la diferencia definitiva entre ambos. Mientras Andrew adquiere el rol de villano, Matt asume el papel de superhéroe. Esta identificación tiene que ver con la actitud de cada uno de ellos con respecto a la ciudad y sus ciudadanos: Andrew se ha entregado a un exterminio sistemático del entorno urbano -poniendo en peligro a los ciudadanos- y Matt emplea todos sus recursos para detener sus ataques y reducirlo.

No obstante, en alguna ocasión, el superhéroe vacila y abandona la protección de la ciudad (o se lo plantea, o lo desea fuertemente), si bien es cierto que no dura mucho en esta actitud, de lo contrario dejaría de ser un superhéroe para ser simplemente una persona con poderes extraordinarios. Esta etapa, por lo general, es propia de las secuelas cinematográficas; ocurre en Spider-Man 2 (Raimi, dir., 2004) y también en Superman II (Lester, dir., 1980), por ejemplo.

En cualquier caso, en el mito fílmico de los superhéroes, al igual que en una parte importante de las metáforas artísticas posmodernas, existe una cierta imagen del "paraíso artificial urbano" (Popeanga Chelaru 2009). Desde la ciudad de Gotham de Batman (Burton, dir., 1989) hasta la ciudad de Nueva York de Spider-Man (Raimi, dir., 2002), los superhéroes combaten la corrupción, pero en rara ocasión luchan contra el sistema que permite su existencia 
(Peterson y Park 2008: 13) y, desde luego, nunca intentarán destruir la ciudad en busca de un bien mayor.

Popeanga señala una característica de la ciudad moderna y posmoderna que será clave a la hora de conocer el valor y la imagen de la ciudad en el cine de superhéroes:

La fascinación por lo "alto", antaño proyectado por las "torres" de las fortalezas, templos o palacios, cuya altura representaba la culminación de un ascenso a través de una escalera (con todo el simbolismo que ello encierra), en la ciudad moderna (y no digamos en la postmoderna) se convierte en la atracción por la torre de acero y cristal oscuro. (Popeanga Chelaru 2009)

Hemos escogido casos representativos de películas de superhéroes para ejemplificar las ideas recogidas en el presente texto. A no ser que señalemos que dichos ejemplos son excepciones, siempre vendrán a representar alguna característica habitual del relato fílmico del superhéroe.

\section{La ciudad como signo de los valores democráticos}

Podemos distinguir dos tipos de superhéroes atendiendo a los beneficiarios de su acción salvadora. En primer lugar, los protectores de la ciudad (o el Estado), como Peter Parker/Spider-Man, protector de la ciudad de Nueva York. En segundo lugar, encontramos a los superhéroes protectores del mundo. Aunque estén afincados en una ciudad, estos superhéroes combaten una amenaza que pone en peligro al resto del mundo (a veces, incluso, a varios planetas). Los Cuatro Fantásticos en Fantastic Four: Rise of the Silver Surfer (Ottman, dir., 2007), por ejemplo, protegen a la Tierra de la amenaza de Gallactus, un ser que se alimenta de planetas.

La ciudad por excelencia en la que se desarrolla la contienda entre superhéroes y villanos es Nueva York, una de las urbes más emblemáticas del mundo occidental $y$, por lo tanto, encarnación de una forma muy concreta de entender la vida, en la que los valores democráticos de la justicia y la libertad tienen una importancia capital. El superhéroe lucha contra quienes ponen en peligro la subsistencia de estos valores: los villanos. En este sentido, cabe señalar que existe una semejanza entre los peligros que acechan a la ciudad y al mundo entero -su exterminio físico, la destrucción de las instituciones o la desaparición de las personas que garantizan la democracia-, y, por tanto, se establece una cierta identificación entre un neoyorquino y cualquier terrícola, es decir, de alguna forma, se universaliza el relato.

El mito de Batman en el cine ofrece buenos ejemplos de atentados contra los valores democráticos significados en la ciudad. El Batman de Burton muestra una reflexión en torno a la corrupción 
de Gotham, "una ciudad gótica, oscura y asfixiante, que viene a expresar que Batman es un producto surgido de esa podredumbre y retorcimiento" (Alba 2005: 8), igual que el villano, Joker, que aspira a ejercer un control opresivo -destructivo, incluso- sobre los ciudadanos.

La amenaza de Gotham en la adaptación llevada a cabo por Nolan, Batman Begins (Nolan, dir., 2005), es la Liga de las Sombras, una organización que durante siglos ha exterminado uno tras otro los núcleos urbanos que habían llegado a su decadencia; ellos fueron los responsables del incendio de Roma y la peste en Europa. Los enemigos de Batman, pues, son gentes con una visión polémica de la existencia, muy heracliteana, muy dialéctica. En la tercera película de la saga, The Dark Knight Rises (Nolan, dir., 2012), la Liga de las Sombras intenta destruir Gotham por medio de la explosión de un gran artefacto construido por Industrias Wayne, pero, previamente, provocan una situación social muy inestable (de terror e injusticia) que deja a los ciudadanos completamente desprotegidos. Nolan muestra de esta forma que el caos y la pérdida de los valores democráticos son previos a la destrucción de la ciudad.

¿Por qué en Watchmen (Snyder, dir., 2009) Ozimandias, que pertenece al grupo de los superhéroes, en realidad es el villano? Porque pretende salvar al mundo de la III Guerra Mundial aniquilando a millones de personas, creando falsamente un enemigo común a las potencias del planeta para, así, unirlos y evitar la guerra. Queriendo hacer el bien, consigue todo lo contrario (Skoble 2010: 74). En cualquier caso, el villano suele ser un fundamentalista, frío (dispuesto a todo para conseguir su fin), y poco democrático (Lucerga 2004).

Hemos visto en The Dark Knight Rises que en la defensa de los valores democráticos está implícita la idea de justicia y protección de los débiles (Reynolds 1994: 14), y en esta relación descubrimos que el superhéroe profesa mayor devoción por la justicia que por la ley (motivo de tormentosas relaciones con el poder político establecido) (Reynolds 1994: 15): Batman quebranta la ley, pero lo hará en la misma medida en que la ley proteja a los criminales e impida la búsqueda real de la justicia (Skoble 2010: 62-63). El ideal de justicia está por encima de la burocracia y las leyes del momento.

El superhéroe posee una gran capacidad destructiva, lo que preocupa a las instituciones gubernamentales. En $X$-Men 3: The Last Stand (Ratner, dir., 2006), el presidente de los EE.UU. conversa con McCoy/Bestia y le expresa de esta manera dicha incertidumbre: "Me preocupa la subsistencia de la democracia cuando un hombre mueve ciudades con la mente". Por su parte, superhéroes como Tony Stark/Ironman en Iron Man (Favreau, dir., 2008) y Bruce Banner/Hulk en The Incredible Hulk (Leterrier, dir., 2008) intentan que el gobierno y el ejército no tengan acceso a sus descubrimientos científicos, pues temen que su capacidad destructiva se amplifique de 
tal modo que no puedan controlarla (otro peligro para la democracia y la subsistencia de la ciudad). En ambos casos existe una preocupación evidente, pues puede que quien tenga un gran poder no esté capacitado para orientar sus fuerzas en favor de la ciudad. ¿Están los superpoderosos (tanto superhéroes como miembros del aparato estatal) preparados, filosóficamente, para utilizar unas capacidades tan radicalmente potenciadas? El uso despótico de la fuerza, ¿no supone la destrucción de los ideales democráticos y, por tanto, del sustento que constituye lo más elevado y mejor del entorno urbano?

\section{Los planos que retratan la ciudad en el cine de superhéroes}

El retrato cinematográfico de la ciudad responde a la concepción de lo urbano como el medio natural del superhéroe. Por ello, los planos de comienzo de secuencia son grandes planos generales de la ciudad. Los grandes planos generales aéreos -filmados desde helicópterotambién son muy comunes al comienzo de secuencia. Este modo constante de contextualizar lo urbano ofrece una visión privilegiada del motivo de la lucha del superhéroe: la ciudad. Conforme avanza la trama, el plano general aéreo se convierte en un seguimiento delirante del superhéroe moviéndose a toda velocidad, correteando por las azoteas, saltando de edificio en edificio, volando entre ellos, y, en definitiva, diferenciándose del resto de los ciudadanos.

Por tanto, gracias al entorno urbano, descubrimos un aspecto de la relación entre la ciudadanía y el superhéroe que se concreta "[...] en el contraste superior/inferior. El superhéroe nace como la encarnación de la superioridad" (Lucerga 2004). En la secuencia final de Spider-Man se plasma esta idea. Se trata de un plano secuencia prodigioso en el que Spider-Man recorre la ciudad de Nueva York por las alturas, balanceándose gracias a sus telarañas entre los más altos edificios, elevándose sobre la generalidad y terminando su recorrido en lo alto de un rascacielos, encaramado al palo de la bandera de los EE.UU. La atmósfera del atardecer otorga a la imagen de Spider-Man, y a la bandera americana, un halo legendario que confirma la superioridad del justiciero y de lo americano.

Siguiendo este patrón de la altura y la superioridad, nos percatamos de que en las zonas elevadas se producen acontecimientos singulares -la boda de Sue Storm/Mujer Invisible, y Reed Richards/Mr. Fantástico (Fantastic Four 2: Rise of the Silver Surfer)-, además de ser el lugar donde tienen su residencia los superhéroes (Fantastic Four), o los villanos. La gran altura de los edificios también suele ser una señal de prueba y superación para el superhéroe. En X-Men Origins: Wolverine (Hood, dir., 2009), Lobezno (retratado en plano cenital) se ve obligado a ascender por unas escaleras de caracol para acceder a la batalla final, mostrando así que 
el gran desarrollo vertical de la construcción es imagen del desafío al que se enfrenta.

También es común que la altura y grandiosidad de los edificios que son sede de instituciones y empresas científicas provoque fascinación en el alter ego del superhéroe (su identidad civil) antes de que reciba sus poderes. Esta fascinación es plasmada cinematográficamente utilizando las panorámicas verticales (movimiento de cámara en su eje vertical) que recorren el edificio de arriba a abajo, o viceversa, situando al personaje en dicha relación de asombro frente a la gran estructura. En The Amazing Spider-Man (Webb, dir., 2012), Webb utiliza este plano en la secuencia en la que Peter Parker entra en las instalaciones científicas donde es picado por la araña radiactiva.

Cuando se trata de películas protagonizadas por equipos de superhéroes, los escenarios cambian y las fronteras se borran; mientras que las batallas de Spider-Man se ciñen a los límites de la ciudad de Nueva York, no sucede lo mismo en Hellboy (Del Toro, dir., 2004) o X-Men (Singer, dir., 2000). En estas películas de varios superhéroes es habitual que sus protagonistas viajen y luchen por diversas partes del planeta, ya que de esta forma se significa que su lucha es universal. En Fantastic Four: Rise of the Silver Surfer encontramos un buen ejemplo de cómo lo fundamental de la realización audiovisual de las batallas y las persecuciones en las alturas de la ciudad se mantiene en el contexto de la jungla o la selva.

Otra característica propia de las películas de equipos de superhéroes es la presencia de los superpoderosos en los bares de ciudad -especialmente importante en los casos de Logan/Lobezno (saga X-Men) y Ben/Cosa (Fantastic Four y Fantastic Four: Rise of the Silver Surfer)-, situación casi inexistente en las películas de un único superhéroe. Además, en ambos casos (Logan/Lobezno y Ben/Cosa) las personas del bar identifican a los superhéroes como seres con poderes extraordinarios. La cercanía de los superhéroes y los ciudadanos está significada en estas visitas a los bares, lugares donde unos y otros, sabiendo lo diferentes que son entre sí, intentan hacer vida en común, aunque no lo consigan.

El ámbito del bar, por lo tanto, supone un lugar de encuentro, donde el superhéroe no es cinematográficamente retratado en relación de superioridad con respecto a los que no son como él. Los directores abandonan la realización grandilocuente y optan por el clásico plano y contraplano de conversación. Además, las secuencias en los bares nos permiten apreciar una diferencia: en las películas de grupos de superhéroes los ciudadanos saben de la existencia de los superhéroes, establecen -tormentosas- relaciones con ellos y los identifican como parte de un grupo social muy reducido; por otro lado, en las películas con un único superhéroe, no es posible 
encontrar esta actitud por ambas partes, y es así, precisamente, por la existencia casi en exclusiva del superhéroe protagonista.

\section{La ciudad como escenario de la lucha}

La mayoría de las grandes batallas tienen por escenario la ciudad, lo que posibilita que los ciudadanos sean testigos de ellas. Tomando como referencia la ciudad, existen cuatro lugares donde se desarrollan los enfrentamientos, cada uno con su significado: las alturas, las calles, el submundo urbano y los lugares de la periferia urbana, o fuera de la ciudad (rodeados de naturaleza).

Las batallas finales que se liberan en lo alto de los edificios son concreciones narrativas de la superioridad del superhéroe en diálogo con la realidad de la ciudad. Algunos combaten en lo alto de majestuosas iglesias como Daredevil/Matt Murdock en Daredevil (Steven, dir., 2003). Otros litigan en las azoteas de edificios imponentes, como Bruce Banner/Hulk (The Incredible Hulk). La tendencia al enfrentamiento de altura es consecuencia, también, de esa fascinación por "los edificios de hierro y de cristal" (Popeanga Chelaru 2009) tan propia de la ciudad moderna y que la ciudad posmoderna hereda. En las batallas finales de las películas de Sam Raimi, por ejemplo, es habitual encontrar la estructura de hierro de un edificio en construcción como escenario de la contienda.

Por otro lado, también es usual que los lugares de lucha sean los cielos urbanos y los espacios elevados entre edificios, como en Chronicle, Iron Man o The Avengers (Whedon, dir., 2012). El caso de la obra de Whedon es de especial importancia, ya que, por la fuerza de sus imágenes, muestra con una mayor exageración que otras películas -de superhéroes- la destrucción de la ciudad de Nueva York, una situación clásica del cine de catástrofes y contiendas urbanas. Cabría señalar en este punto la influencia que han tenido en los cineastas norteamericanos los atentados del 11 de septiembre de 2001 en el World Trade Center.

En otras ocasiones, el escenario de la batalla es la calle. En el caso de Fantastic Four, la contienda en las calles supone otro factor más de cercanía entre los cuatro superhéroes y el resto de la población, aparte del contexto del bar. En la batalla final contra Víctor von Doom, los superhéroes se sirven de los elementos que les ofrece el entorno urbano para derrotar al villano, es decir, salvan a la ciudad sin elementos extraños a ella. También hemos podido ver al Batman de Nolan luchando en las calles de su ciudad, pero con un significado diverso al de Los Cuatro Fantásticos: Batman lucha en las calles significando así su contacto con lo más bajo.

En el caso de Thor (Branagh, dir., 2011) -el mito de Thor en el cine- la contienda en las calles tiene un significado diverso. El beligerante dios nórdico Thor es desterrado de Asgard por su padre, Odín, y despojado de sus poderes, debido a su carácter soberbio y 
arrogante. Debe hacerse valedor de su dignidad de dios y, para ello, será necesario que se abaje y abandone su orgullo y vanidad. Ese abajamiento está significado en el contexto en el que aterriza: un pequeño pueblo en el desierto estadounidense. Ni siquiera aterriza en una ciudad. En este caso, la presencia del pueblo es, en realidad, ausencia de la ciudad. Hasta ese punto debe rebajarse Thor: no descubrirá el verdadero valor de la humildad protegiendo la ciudad de Nueva York, sino litigando en las polvorientas calles de un pueblucho.

Las calles, además, suelen ser lugares donde los superhéroes menos dotados, o aquellos que aspiran a ser superhéroes, comienzan sus hazañas. Ocurre así en The Green Hornet (Gondry, dir., 2011), Kick-Ass (Vaughn, dir., 2010) y Mystery Men (Usher, dir., 1999). La incapacidad de estos aspirantes a justiciero por librar sus batallas en lugares más elevados los sitúa al nivel de sus conciudadanos, mostrando, así, que no son tan diferentes de aquellos a los que pretenden defender. Cuando son los villanos los que carecen de habilidades extraordinarias, el superhéroe también lucha a nivel del suelo, como en Hancock (Berg, dir., 2008). batallas:

Bajo las calles se encuentran otros escenarios habituales en las

Así como los paraísos artificiales parecen estar relacionados con el concepto de altura y luz (aunque sea también artificial), lo urbano conoce, desde los tiempos de la ciudad premoderna, un trasfondo infernal, la existencia de un paisaje urbano subterráneo. (Popeanga Chelaru 2009)

La lucha de Hellboy contra el monstruo de la resurrección comienza en un museo, pero se desarrolla mayormente en las profundidades de la ciudad, en sus cloacas. Hellboy (Del Toro, dir., 2004) nos muestra que las características del superhéroe condicionan fuertemente el lugar de la ciudad en el que lucha: él es un demonio, por lo que el lugar natural de su lucha no son los cielos ni los lugares elevados, sino el inframundo, los lugares ocultos y siniestros. Así ocurre también en Hellboy 2: The Golden Army (Del Toro, dir., 2008) donde parte de su trama se desarrolla en una ciudad -fantásticasubterránea, que se encuentra bajo Nueva Jersey; la batalla final, además, se desarrolla en una amplia estancia escondida bajo una pradera.

La lucha entre Peter Parker/Spider-Man y el Dr. Curt Connors/El Lagarto (The Amazing Spider-Man) también se desarrolla en un lugar subterráneo: las cloacas de Nueva York. A pesar de que Spider-Man es el superhéroe de las telarañas y la altura, el que se desliza entre los edificios, el contexto de la cloaca también es propio de las arañas afincadas en la ciudad. El carácter clandestino del cuartel general del villano y el animal al que se asemeja cuando se transforma (un 
lagarto) también podrían constituir otros argumentos que justifiquen el sentido de este contexto anómalo en la filmografía del hombre araña.

En cuarto lugar, las batallas también tienen por escenario la periferia de la ciudad, los entornos naturales, e, incluso, lugares fuera del planeta Tierra. Se trata de contextos habituales en las películas de grupos de superhéroes y casi inexistentes en las películas de un solo superhéroe. Retomando la clasificación que hicimos al comienzo, la cual elaboramos atendiendo a los beneficiarios de la acción salvadora del superhéroe (protectores de la ciudad y protectores del mundo), podemos señalar que un superhéroe protector del mundo suele estar acompañado por otros superhéroes.

La saga X-Men es uno de los máximos exponentes de esta tendencia; algunos de los lugares donde se desarrollan las luchas finales son: la Estatua de la Libertad (X-Men), las instalaciones paramilitares secretas del lago Alcaline, en medio de las montañas en $X$-Men 2 (Singer, dir., 2003)-, la isla donde se encontraba la antigua prisión de Alcatraz (X-Men 3 ) y un laboratorio siniestro en una isla perdida -"la Isla de las Tres Millas, oculta al mundo entero"( $X$-Men Origins: Wolverine).

El encuentro final de Watchmen -cuando Dr. Manhattan destruye a Rorschach- también se produce lejos de la ciudad, en unas instalaciones secretas regentadas por Ozimandias en medio de un paraje nevado y desértico. The Incredibles (Bird, dir., 2004) también combaten fuera de la ciudad, en medio de una jungla repleta de robots y máquinas de destrucción. En The Avengers, el tramo final de la contienda entre los superhéroes y los villanos también se desarrolla más allá de la atmósfera terrestre.

En un primer momento podría parecernos que el caso de Green Lantern (Campbell, dir., 2011) es una excepción a esta tendencia, ya que Hal Jordan/Linterna Verde (un superhéroe aparentemente solitario) conduce a su enemigo hasta la superficie del Sol para destruirlo -un lugar más allá de la ciudad-. Y lo consigue. No obstante, en esa misma secuencia, el superhéroe es rescatado por otros miembros del equipo intergaláctico de Linternas Verdes, pues, exhausto tras la batalla, queda indefenso ante la fuerza de atracción del Sol. Hal Jordan/Linterna Verde no es el único guardián con facultades extraordinarias, hay otros como él. Todos ellos actúan corporativamente (como un grupo de superhéroes) y luchan por la paz y la justicia en el cosmos. 


\section{Los medios de comunicación: conciencia colectiva de la ciudad}

Para terminar, y a modo de conclusión, cabe señalar que los medios de comunicación son un elemento fundamental para comprender la relación entre el superhéroe y la ciudad.

A través de ellos, los ciudadanos saben de la existencia de los superhéroes. Por esta razón, la relación de los ciudadanos con el superhéroe está fuertemente condicionada por la imagen de éste en los medios. Los medios de comunicación integran al superhéroe, como parte del relato urbano, en la conciencia colectiva, informando de si es, o no, una amenaza para los ciudadanos, independientemente de que sea verdad. El criterio teledirigido de la ciudadanía en el cine de superhéroes tiene mucho que ver con las tesis expuestas por Giovanni Sartori en Homo videns. La sociedad teledirigida (2008). Además, como veremos, las características de la información televisiva señaladas por Sartori -subinformación, desinformación, falseamiento de la verdad (Sartori 2008: 103-106)-, en el cine de superhéroes, no sólo están presentes en la televisión, también en la prensa escrita y la radio.

Los medios de comunicación, por tanto, unen a los ciudadanos en una forma concreta de acceso a la realidad. Y su influencia es poderosa. Tanto que llegan incluso a separar al superhéroe de su familia, como en el caso de Bobby Drake/Iceman en X Men 2.

Los medios de comunicación son los agentes que relacionan realidades. Esta característica de los medios está presente en la estructura interna del relato, que los emplea como bisagra narrativa al comienzo de las secuencias: recoge lo anterior, lo juzga e introduce lo nuevo. Es habitual que las secuencias comiencen con planos detalle de portadas de prensa escrita o pantallas de televisión cuyos titulares hacen referencia a hechos de las secuencias inmediatamente anteriores. Con ello se contextualiza la nueva situación, mostrando al espectador qué parcela de la realidad ha sido tomada por el todo y presentada a la audiencia. El titular de un medio de comunicación dentro del relato fílmico del superhéroe, en definitiva, informa al espectador cinematográfico sobre la opinión que la mayor parte de los ciudadanos ha absorbido. En este sentido, resulta especialmente elocuente el comentario que John Allerdyce/Pyro le hace a un policía en $X$ Men 2 antes de utilizar su poder para atacar: "¿Ha oído hablar en la televisión de esos peligrosos mutantes?". El espectador de X-Men 2 sabe que hay mutantes peligrosos y otros que son auténticos héroes, mientras que a los espectadores televisivos de los noticiarios de $X$-Men 2 se les ha presentado una parte de la realidad como si fuera la totalidad de la misma. Y ellos lo han creído, porque la imagen (parece que) no miente (Sartori 2008: 103). 
Por otro lado, los superhéroes tienen conciencia de sí mismos, el alcance de sus acciones y el lugar que ocupan en la conciencia colectiva gracias a los medios. Además, las decisiones del superhéroe, en muchas ocasiones, están fuertemente influidas por las noticias. Es muy usual, sobre todo durante el ecuador de la historia, que a mitad de secuencia, el superhéroe, en su identidad civil, protagonice la siguiente situación: la televisión está encendida y sintonizada en un canal en el que se están emitiendo noticias, el presentador del noticiario da una información vinculada con el superhéroe (a veces se le nombra y otras tan sólo se trata de información de vital importancia para el protagonista), el superhéroe toma una decisión que le implica en su papel de salvador de la ciudad.

Los argumentos de las películas de superhéroes están invadidos por los medios de comunicación, desde el primer superhéroe -KalEl/Superman/Clark Kent en Superman: The Movie (Donner, dir., 1978) es periodista y trabaja en el Daily Planet- hasta los más actuales y atípicos justicieros -en Kick-Ass la televisión hace un seguimiento tan exhaustivo del superhéroe que, incluso, retransmiten en directo su ejecución-. Recordemos, por ejemplo, el caso de la saga Ironman. En la primera película, Iron Man, llegamos a presenciar hasta tres ruedas de prensa, multitud de apariciones en medios y varios desfiles de periodistas; incluso el mismo Tony Stark/Ironman es informado de los movimientos comerciales de su propia empresa gracias a una periodista de la revista Vanity Fair (con quien ha mantenido relaciones sexuales) antes que por su junta directiva.

En ocasiones, la presencia de los periodistas y los medios de comunicación es tan exagerada que parece cosa de magia, como en Fantastic Four, donde los operadores de cámara de televisión aparecen en el momento justo para retratar las inesperadas hazañas de los superhéroes, apenas unos instantes después del comienzo de los hechos; además, son capaces de emitir una información ocurrida hace escasos minutos, no mediante una retransmisión en directo, sino a través de una pieza perfectamente montada y rotulada. La acusada presencia de los medios de masas en la actividad de estos superhéroes es la manera de mostrar que la vida de Los Cuatro Fantásticos es patrimonio de la ciudad. Su pertenencia a la ciudad es tal que en un canal de televisión se atreven a ponerles nombre y se refieren a ellos como Los Cuatro Fantásticos. Así son los medios en el cine de superhéroes: muestran algo y lo nombran, creando una forma homogénea de referirse y ver la realidad, sea verdad o mentira.

Quizá una de las mayores exageraciones sobre la omnipresencia de la prensa sea un momento de Hellboy en el que se muestra una visión de un futuro apocalíptico. Un travelling lateral 
(desplazamiento lateral del punto de vista) va mostrando una ciudad completamente arrasada. Entre los escombros aparece un periódico, levemente sacudido por el viento, cuyo titular es "Apocalipsis". Es el fin del mundo, pero la prensa escrita ha tenido capacidad para mover toda su maquinaria y lanzar una edición informando de ello con la velocidad propia de la prensa digital o de Twitter.

En la saga de Spider-Man dirigida por Raimi encontramos un caso paradigmático de crítica a la prensa. J. Jonah Jameson, el editor del periódico en el que trabaja Peter Parker/Spider-Man como fotógrafo, ofrece constantemente una imagen negativa del superhéroe y le acusa de amenaza social. A través de sus prácticas sensacionalistas, Jameson retrata a Spider-Man como un supervillano y los lectores del periódico no son inmunes a sus publicaciones. El editor es el paradigma del hombre práctico: sólo le interesa ganar dinero con la venta de los periódicos, aunque las noticias sean falsas (Morris 2010: 255-256). La crítica a los medios en la saga X-Men también explora esa dimensión adulterada de las informaciones periodísticas, mostrándose en íntima relación con la información política.

La ciudad, por tanto, entendida como el conjunto de las personas que la habitan, conoce la realidad tal y como la presenta el discurso periodístico. Dicho discurso, en relación a los superhéroes (salvo en excepciones como las frivolidades a las que se entrega la prensa en Fantastic Four: Rise of the Silver Surfer), siempre da respuesta a la misma cuestión: el superhéore, ¿amenaza a la ciudad o es su guardián, su vigilante bondadoso? Por un lado, en pocas ocasiones aparecen personajes que cuestionen la información dada por los medios $y$, por otro lado, en muchos momentos, somos testigos de la incapacidad de los periodistas para conocer la verdad de los hechos de los que hablan y que son aceptados acríticamente por los ciudadanos; véanse, por ejemplo, casos como el del periodista Alexander Knox (Batman) o Eddie Brock en Spider-Man 3 (Raimi, dir., 2007).

Si tenemos en cuenta la imagen de los medios en el cine de superhéroes como último elemento de nuestro análisis, podemos concluir que poco importa dónde se desarrolle la lucha, o si los superhéroes frecuentan bares de copas, o si profesan secreta devoción por el gran desarrollo vertical de los edificios; al final quedan dos cosas: las consecuencias reales de sus acciones (en su ser y en la ciudad), y lo que cuenten los medios de comunicación (la conciencia de la ciudad, como se ha visto, de criterio cuestionable). 


\section{Bibliografía}

ALBA, Federico (2005): "Héroes del cómic: ¿reflejo o ideales?". Pantalla 90, núm. 44, pp. 4-9.

LUCERGA PEREZ, María José (2004): "Del uniforme del Capitán América al azul desnudo del Dr. Manhattan: ascenso y caída del superhéroe como principio de construcción identitaria" [en línea]. Tonos digital: Revista electrónica de estudios filológicos, núm. 8. En: http://www.um.es/tonosdigital/znum8/estudios/13-supertonos.htm [Consulta: enero de 2013].

MORRIS, Tom; y MORRIS Matt (eds.) (2010): Los superhéroes y la filosofía. Madrid: Blackie Books.

ORELLANA, Juan; y MARTÍNEZ LUCENA, Jorge (2010): Celuloide posmoderno. Narcisismo y autenticidad en el cine actual. Madrid: Encuentro.

PETERSON, Christopher; y PARK, Nansook (2008): "The positive psychology of superheroes", en Robin S. Rosengerg (ed.), The Psychology of Superheroes: An Unauthorized Exploration, pp. 5-18. Dallas: Perseus Distribution Services.

POPEANGA CHELARU, Eugenia (2009): "Modelos urbanos: de la ciudad moderna a la ciudad posmoderna" [en línea]. Ángulo Recto. Revista de Estudios sobre la ciudad como espacio plural, vol. 0. En: http://pendientedemigracion.ucm.es/info/angulo/volumen/Volum en0/articulos01.htm [Consulta: febrero de 2013].

REYNOLDS, Richard (1994): Super Heroes. A Modern Mythology. Mississippi: University Press of Mississippi.

SARTORI, Giovanni (2008): Homo videns. La sociedad teledirigida. Madrid: Taurus.

SKOBLE, Aeon J. (2010): "Revisionismo de superhéroes en Watchmen y The Dark Knight Returns", en Tom Morris y Matt Morris (eds.), Los superhéroes y la filosofía, pp. 59-77. Madrid: Blackie Books.

\section{Filmografía}

BERG, Peter (dir.) (2008): Hancock. EE.UU.: Columbia Pictures / Forward Pass / Overbrook Entertainment.

BIRD, Brad (dir.) (2004): The Incredibles. EE.UU.: Walt Disney Pictures / Pixar Animation Studios.

BRANAGH, Kenneth (dir.) (2011): Thor. EE.UU.: Marvel Studios / Paramount Pictures.

BURTON, Tim (dir.) (1989): Batman. EE.UU.: Warner Bros. Pictures / PolyGram Filmed Entertainment.

CAMPBELL, Martin (dir.) (2011): Green lantern. EE.UU.: DC Comics / Warner Bros. Pictures.

DEL TORO, Guillermo (dir.) (2004): Hellboy. EE.UU.: Sony Pictures.

- (2008): Hellboy 2: The Golden Army. EE.UU.: Universal Pictures.

DONNER, Richard (dir.) (1978): Superman: The Movie. Reino Unido: Dovemead Films / Film Export A.G. / International Film Production.

FAVREAU, John (dir.) (2008): Iron Man. EE.UU.: Paramount Pictures / Marvel Enterprises / Goldman \& Associates. 
GONDRY, Michel (dir.) (2011): The Green Hornet. EE.UU.: Columbia Pictures / Original Film.

HOOD, Gavin (dir.) (2009): X-Men Origins: Wolverine. EE.UU.: 20th Century-Fox / Donners' Company / Dune Entertainment / Marvel Enterprises / Seed Productions.

LESTER, Richard (dir.) (1980): Superman II. EE.UU.: Dovemead Films / Film Export A.G. / Internacional Film Productiom.

LETERRIER, Louis (dir.) (2008): The Incredible Hulk. EE.UU.: Universal Pictures / Marvel Enterprises.

NOLAN, Christopher (dir.) (2005): Batman Begins. EE.UU.: Warner Bros. Pictures.

- (2012): The Dark Knight Rises. EE.UU.: DC Entertainment / Legendary Pictures / Warner Bros. Pictures.

OTTMAN, John (dir.) (2007): Fantastic Four: Rise of the Silver Surfer. EE.UU: 20th Century Fox.

RAIMI, Sam (dir.) (2002): Spider-Man. EE.UU.: Columbia Pictures / Marvel Entertainment / Laura Ziskin Production.

- (2004): Spider-Man 2. EE.UU.: Marvel Entertainment.

- (2007): Spider-Man 3. EE.UU.: Sony Pictures.

RATNER, Brett (dir.) (2006): X-Men 3: The Last Stand. EE.UU.: 20th Century Fox.

SINGER, Bryan (dir.) (2000): X-Men. EE.UU.: 20th Century Fox / Marvel Entertainment Group.

- (2003): X-Men 2. EE.UU.: 20th Century Fox.

SNYDER, Zack (dir.) (2009): Watchmen. EE.UU.: Warner Bros. Pictures / Paramount Pictures / Legendary Pictures / DC Comics.

STEVEN JOHNSON, Mark (dir.) (2003): Daredevil. EE.UU.: 20th Century Fox.

STORE, Tim (dir.) (2005): Fantastic Four. EE.UU.: 20th Century Fox / Marvel Enterprises / 1492 Pictures.

TRANK, Josh (dir.) (2012): Chronicle. EE.UU.: 20th Century Fox.

USHER, Kinka (dir.) (1999): Mystery Men. EE.UU.: Universal Pictures / Lawrence Gordon.

VAUGHN, Matthew (dir.) (2010): Kick-Ass. EE.UU.: Lionsgate Films / Marv Films / Plan B Entertainment.

WEBB, Marc (dir.) (2012): The Amazing Spider-Man. EE.UU.: Sony Pictures / Columbia Pictures / Marvel Studios.

WHEDON, Joss (dir.) (2012): The Avengers. EE.UU.: Marvel Studios / Paramount Pictures. 